\title{
First complete sauropod dinosaur skull from the Cretaceous of the Americas and the evolution of sauropod dentition
}

\author{
Daniel Chure • Brooks B. Britt • John A. Whitlock • \\ Jeffrey A. Wilson
}

Received: 21 October 2009 /Revised: 15 January 2010 /Accepted: 16 January 2010 /Published online: 24 February 2010

(C) The Author(s) 2010. This article is published with open access at Springerlink.com

\begin{abstract}
Sauropod dinosaur bones are common in Mesozoic terrestrial sediments, but sauropod skulls are exceedingly rare - cranial materials are known for less than one third of sauropod genera and even fewer are known from complete skulls. Here we describe the first complete sauropod skull from the Cretaceous of the Americas, Abydosaurus mcintoshi, n. gen., n. sp., known from 104.46 $\pm 0.95 \mathrm{Ma}$ (megannum) sediments from Dinosaur National Monument, USA. Abydosaurus shares close ancestry with Brachiosaurus, which appeared in the fossil record ca. 45 million years earlier and had substantially broader teeth. A survey of tooth shape in sauropodomorphs demonstrates that sauropods evolved broad crowns during the Early Jurassic but did not evolve narrow crowns until the Late Jurassic, when they occupied their greatest range of crown breadths. During the Cretaceous, brachiosaurids
\end{abstract}

Electronic supplementary material The online version of this article (doi:10.1007/s00114-010-0650-6) contains supplementary material, which is available to authorized users.

\section{Chure}

Dinosaur National Monument,

P.O. Box 128, Jensen, UT 84035, USA

B. B. Britt

Museum of Paleontology and Department of Geological Sciences, Brigham Young University,

S-389 ESC, P.O. Box 24606, Provo, UT 84602-4606, USA

J. A. Whitlock · J. A. Wilson $(\bowtie)$

Museum of Paleontology and Department of Geological Sciences, University of Michigan,

1109 Geddes Avenue,

Ann Arbor, MI 48109-1079, USA

e-mail: wilsonja@umich.edu and other lineages independently underwent a marked diminution in tooth breadth, and before the latest Cretaceous broad-crowned sauropods were extinct on all continental landmasses. Differential survival and diversification of narrow-crowned sauropods in the Late Cretaceous appears to be a directed trend that was not correlated with changes in plant diversity or abundance, but may signal a shift towards elevated tooth replacement rates and highwear dentition. Sauropods lacked many of the complex herbivorous adaptations present within contemporaneous ornithischian herbivores, such as beaks, cheeks, kinesis, and heterodonty. The spartan design of sauropod skulls may be related to their remarkably small size-sauropod skulls account for only $1 / 200$ th of total body volume compared to $1 / 30$ th body volume in ornithopod dinosaurs.

Keywords Dinosauria - Sauropoda $\cdot$ Cretaceous ·

North America $\cdot$ Herbivory Tooth shape

\section{Introduction}

Sauropod dinosaurs were the predominant megaherbivores during ca. 140 million years of the Mesozoic, despite their large body size and its attendant biomechanical, physiological, developmental, and ecological consequences. Sauropods achieved a near-global distribution by the Middle Jurassic and diversified into more than 120 species, accounting for approximately one-fifth of non-avian dinosaur diversity (Upchurch et al. 2004).

Perhaps surprisingly, most sauropods possessed only basic adaptations for cropping vegetation that were acquired early in their history and retained in most descendant 
lineages, including enlarged teeth set in broadly arched tooth rows, equal numbers of upper and lower teeth, wrinkled tooth enamel, and precise occlusion (Wilson and Sereno 1998; Upchurch and Barrett 2000). Sauropods lacked the more complex masticatory adaptations for intraoral processing that were present in contemporaneous ornithischian herbivores, such as a keratinous beak supported by neomorphic bones, emarginated cheeks, cranial kinesis, or heterodonty (Sereno 1986). In fact, the presence of beaks (Sereno 2007) and cheeks (Upchurch et al. 2007) in their prosauropod ancestors suggests that sauropods may have lost some of these masticatory adaptations early in their evolutionary history. Tooth breadth is one of the few features related to herbivory that exhibits notable variation within sauropods, which accounts for its use in early classifications of the group into "narrow-crowned" and "broad-crowned" forms. More recent evaluations of sauropod phylogeny, however, have shown that broad crown proportions are primitive (Upchurch 1995), and narrow tooth crown proportions were acquired independently multiple times in the evolutionary history of sauropods (Salgado et al. 1997; Wilson and Sereno 1998).

Here, we describe a new sauropod from Lower Cretaceous sediments of Dinosaur National Monument, USA (Figs. 1 and 2) that records a shift to narrow-crowned teeth in a clade otherwise typified by broad crowns. Known from a complete skull and several partial skulls, the new taxon is closely related to the Late Jurassic Brachiosaurus. Below, we describe this new animal, interpret its phylogenetic affinities, examine the evolution of tooth crown shape in sauropod dinosaurs, and explore its implications for the evolution of herbivory within the group.

\section{Note on taxonomy}

Taylor (2009) recently suggested that the North American species Brachiosaurus altithorax is generically distinct from the African species Brachiosaurus brancai, which is known from abundant material including a complete skull and many craniodental elements. Based on numerous differences between overlapping parts of both holotypes, Taylor (2009) proposed that the African species should be known as Giraffatitan brancai. While we are open to this possibility, we do not believe that it is sufficiently justified at present because the identified differences have not been defended as separating genera, rather than species, populations, or individuals. The sister-taxon relationship between the two species recovered in the phylogenetic analysis performed by Taylor (2009) neither supports nor refutes their generic-level separation. At this point, we consider the decision to recognize the African species as a genus apart to be arbitrary. We choose to retain the original
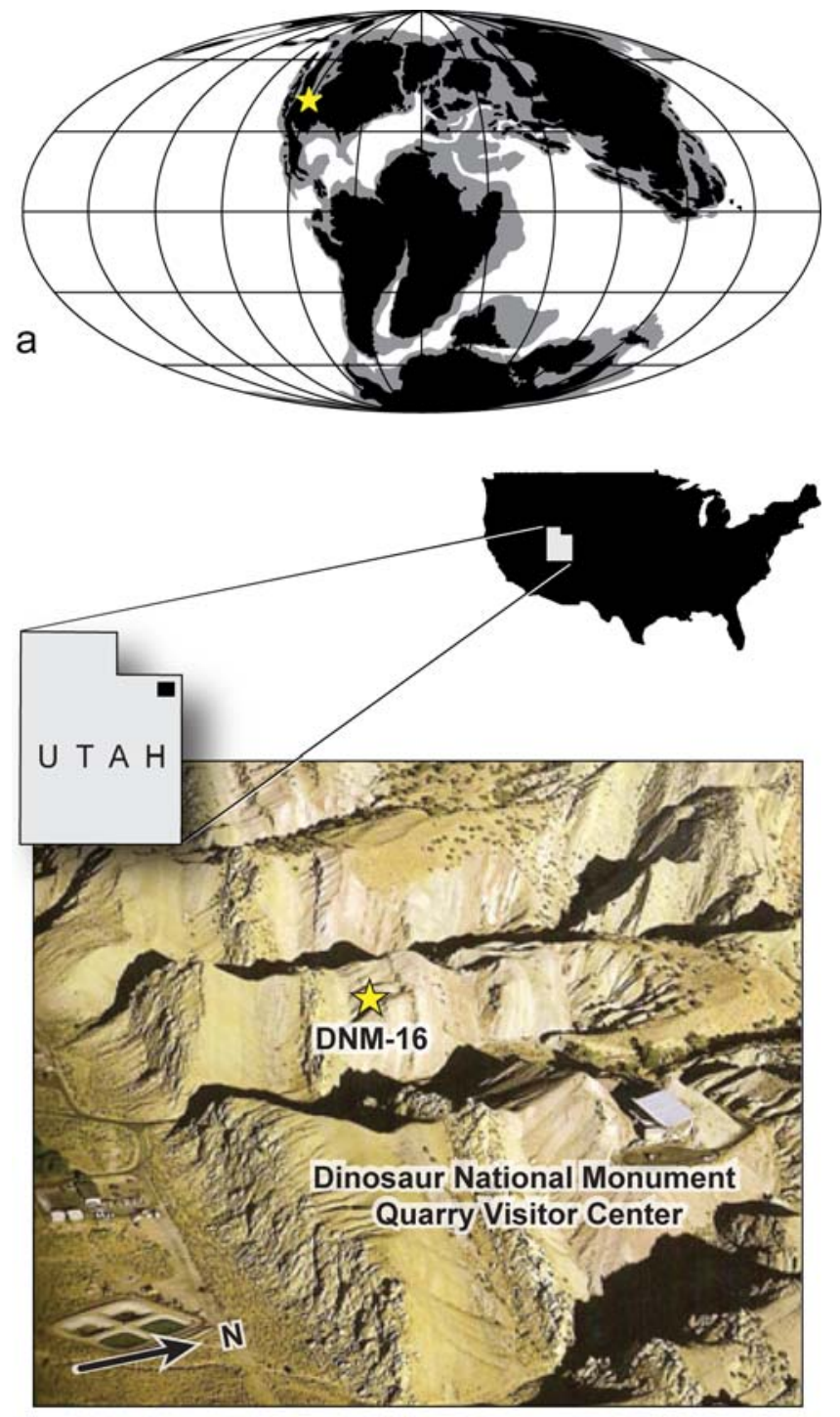

b

Fig. 1 Palaeogeography and exposures of the Cedar Mountain Formation in the area of the Abydosaurus mcintoshi quarry at Dinosaur National Monument, Utah. a Early Cretaceous (120 Ma) paleocoastline map (Mollweide projection) with latitude and longitude lines spaced at $30^{\circ}$ intervals (modified from Blakey 2006). Star identifies position of Dinosaur National Monument. b Photograph of Dinosaur National Monument showing the location of locality DNM 16 (star), which is approximately $375 \mathrm{~m} \mathrm{WSW}$ of the Carnegie Quarry visitor center $\left(40^{\circ} 26^{\prime} 24^{\prime \prime} \mathrm{N}, 109^{\circ} 18^{\prime} 18^{\prime \prime} \mathrm{W}\right)$

nomenclature in this contribution, distinguishing between the two species where appropriate.

\section{Systematic paleontology}

Sauropoda Marsh 1878

Macronaria Wilson and Sereno 1998

Titanosauriformes Salgado et al. 1997

Brachiosauridae Riggs 1904

Abydosaurus mcintoshi gen. et sp. nov. 


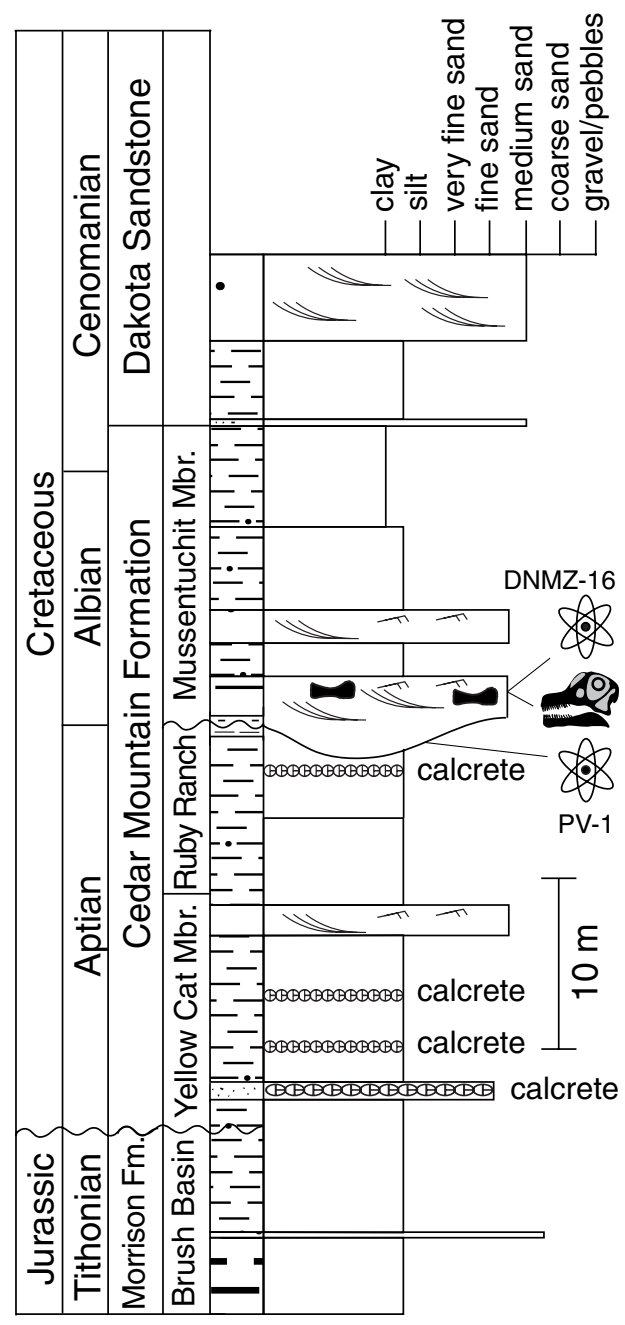

a

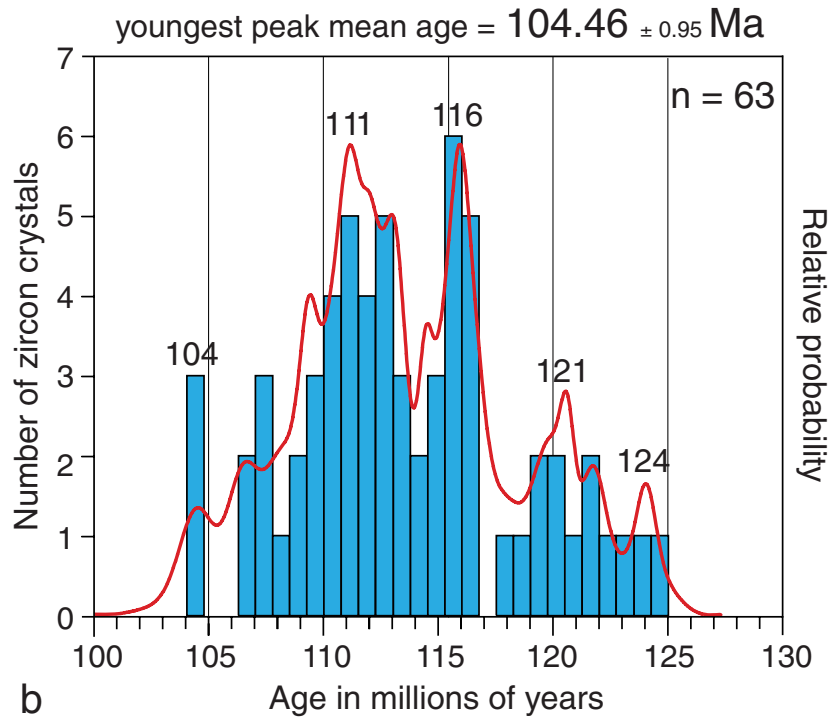

Etymology

The generic name refers to Abydos, the Greek name for the city along the Nile River (now El Araba el Madfuna) that
Fig. 2 Stratigraphy and geochronology of DNM 16. a Stratigraphic section indicating position of skulls and zircon samples DMMZ-16 and PV-1. b Histogram of number of zircon crystals (blue) and relative age probability curve (red) of single crystal detrital zircon $\mathrm{U} / \mathrm{Pb}$ dating of sample PV-1, the mudstone underlying the bone-bearing sandstone; $104.46 \pm 0.95 \mathrm{Ma}=$ Youngest Peak Mean Age, 2 sigma (3 crystals, mean square weighted deviation $=0.0112$, probability $=0.099$ ). See Online Resources 1 and 2 for geochronologic data

was the burial place of the head and neck of Osiris, Egyptian god of life, death, and fertility - an allusion to the type specimen, which is a skull and neck found in a quarry overlooking the Green River; sauros is the Greek word for lizard. The specific name honors Jack McIntosh for his contributions to Dinosaur National Monument and to the study of sauropod dinosaurs.

Holotype

Dinosaur National Monument (DINO) 16488, a nearly complete, articulated skull and lower jaws preserved in articulation with the first four cervical vertebrae (Figs. 3 and 4).

\section{Referred specimens}

Many cranial and postcranial bones were found in association with the holotypic specimen in locality Dinosaur National Monument (DNM) 16, where excavations are ongoing (see Online Resource 3-Fig. 1). Cranial bones pertain to three additional individuals (DINO 17848, 17849, 39727), each of which can be referred to $A$. mcintoshi on the basis of autapomorphies and the absence of substantive differences with the holotype. DINO 17848 (Online Resource 3-Fig. 2a) is the anterior portion of an articulated skull and lower jaws that was sawn through during excavation just anterior to the external nares. It preserves prenarial portions of the right and left premaxillae and maxillae; right and left dentaries; anterior portions of the right and left surangular and angular, right quadrate, pterygoid, and prearticular; and an associated right quadratojugal, ectopterygoid, dentary, splenial, and intercoronoid. DINO 17849 (Online Resource 3-Fig. 3) is a nearly complete, disarticulated skull that includes right premaxilla, jugal, lacrimal, postorbital, and palatine; right and left maxillae; nasals; pterygoids, ectopterygoids, and quadratojugals; left quadrate, a braincase with skull roof; and a complete set of upper teeth preserved as 'dentures'articulated teeth preserved with little or no surrounding dentigerous bones (see Britt et al. 2008). DINO 39727 (Online Resource 3-Fig. 2c) is a braincase with a partial skull roof. The postcranial bones, which include a partial pelvis and sacrum with an articulated tail, a scapula, a humerus, and metacarpus, do not overlap with the holotype, but they were found in close association with DINO 17848 
Fig. 3 Photographs and interpretive line drawings of the holotypic skull of Abydosaurus mcintosh $i$ gen et sp. nov (DINO 16488) in left lateral (a) and right lateral (b) views. Gray tone indicates matrix, hatching indicates broken bone. Abbreviations: $a$ angular, aof antorbital fenestra, asaf anterior surangular foramen, $d$ dentary, en external naris, eo exoccipitalopisthotic, fr frontal, $h$ hyoid, $j$ jugal, la lacrimal,

ls laterosphenoid, lt $f$ lateral temporal fenestra, $m$ maxilla, $n$ nasal, oc occipital condyle, or orbit, os orbitosphenoid, $p$ parietal, paof preantorbital fenestra, $p m$ premaxilla, po postorbital, pop paroccipital process, $p r$ prearticular, $p r f$ prefrontal, psaf posterior surangular foramen, $p t f$ postemporal fenestra, $q$ quadrate, $q j$ quadratojugal, $s a$ surangular, $s c$ scleral plates, $s n f$ subnarial foramen, $s p l$ splenial, splf splenial foramen, $s q$ squamosal
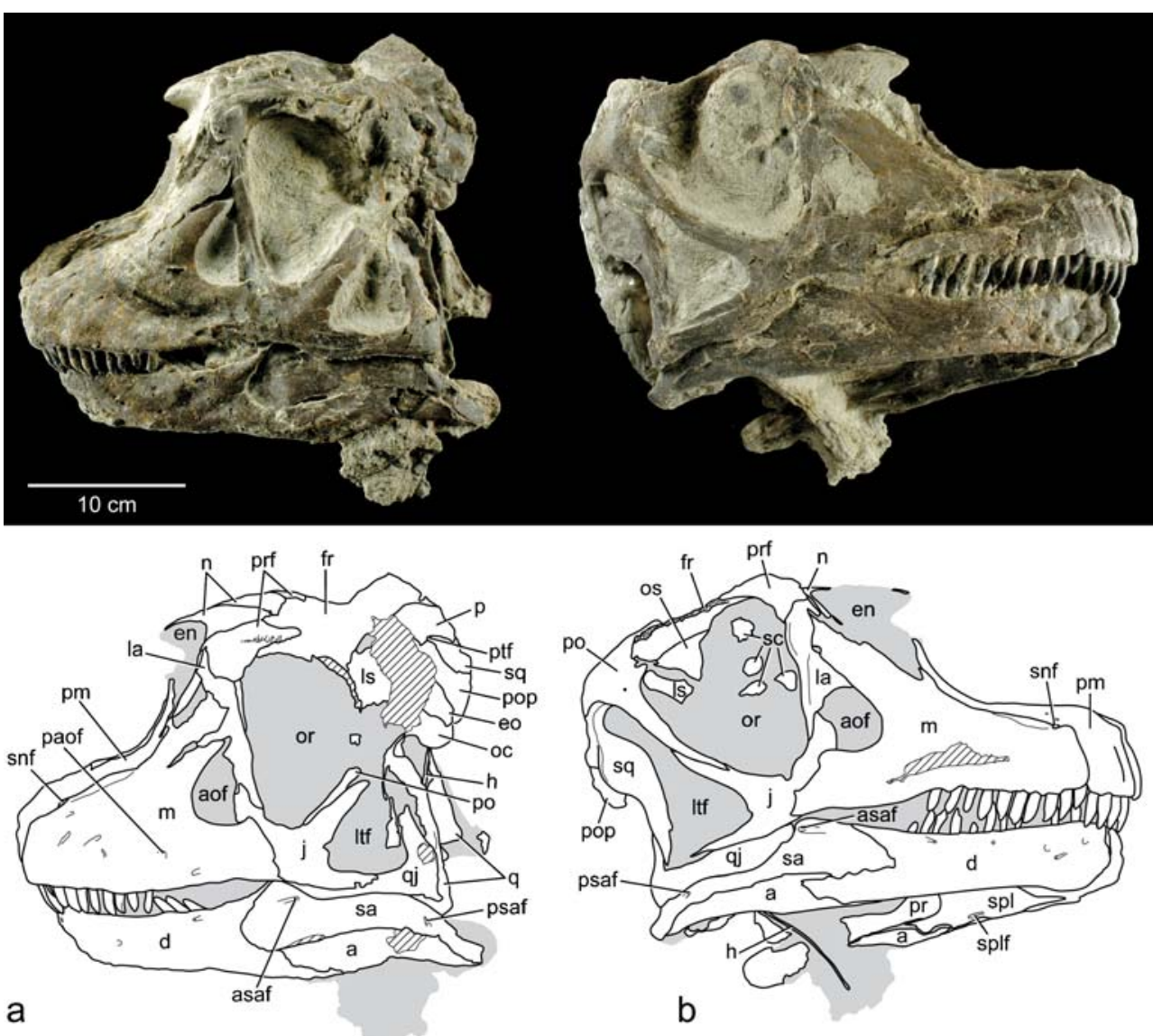

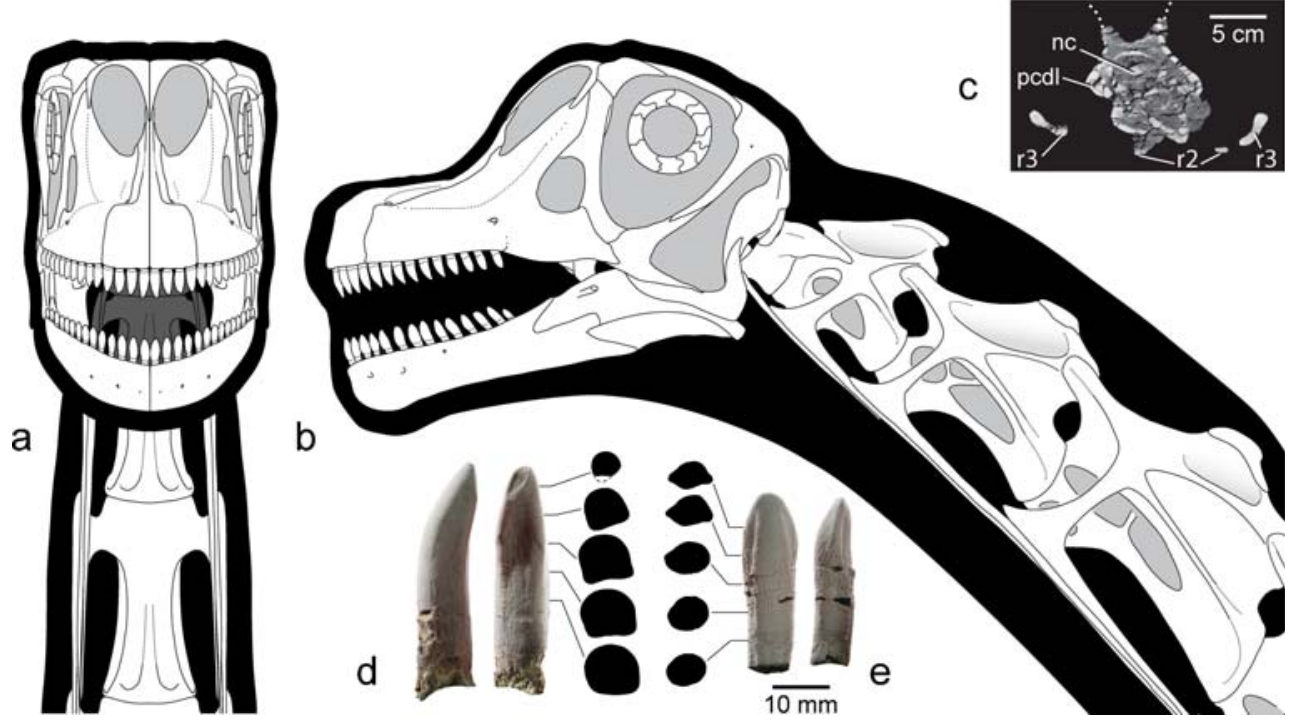

Fig. 4 Reconstruction of the skull of $A$. mcintoshi based on holotypic and referred specimens (DINO 16488, 17848, 17849, 39727) in anterior (a) and left lateral (b) views. Computed tomography crosssection through the third cervical vertebra just posterior to the diapophysis (c) reveals camellate pneumaticity. Photographs of left premaxillary tooth 1 (d) and right dentary tooth 5 (e) in lingual, mesial, and cross-sectional views show differences in tooth shape. Note twisting of carina in the premaxillary tooth, which has an apical wear facet. Cross-sections were taken at $5 \mathrm{~mm}$ intervals along the tooth axis. Abbreviations: $n c$ neural canal, $p c d l$ posterior centrodiapophyseal lamina, $r 2$ cervical rib $2, r 3$ cervical rib 3 
and DINO 17849 (Online Resource 3-Fig. 1). Although we cannot associate them directly with any one individual, their close association with the cranial bones and lack of other sauropod taxa in the quarry indicate that the postcranial bones almost certainly pertain to A. mcintoshi.

Locality, horizon, and age

A. mcintoshi was collected from locality DNM 16, which is located $375 \mathrm{~m}$ WSW of the Carnegie Quarry at Dinosaur National Monument, in Utah, USA (Fig. 1b). The bonebearing horizon is $27 \mathrm{~m}$ above the base of the Cedar Mountain Formation, near the base of the Mussentuchit Member. The bones were preserved in the lower one half of a 3-m thick stack of low angle, trough cross-bedded to laminar-bedded, medium-grained, fluvial sandstones with thin interbeds of mudstone. These sandstones are incised into a $0-2-\mathrm{m}$ thick smectitic mudstone. Together, these mudstones and sandstones mark the base of $12-\mathrm{m}$ thick paleovalley incised into the Ruby Ranch Member of the Cedar Mountain Formation. Single crystal zircon U-Pb dating via LA-ICPMS (Laser Ablation Inductively Coupled Plasma Mass Spectrometry) of three crystals comprising the youngest peak of a total of 63 dated crystals yields a mean age of $104.46 \pm 0.95$ Ma. Thus, the Abydosaurus bone bed can be no older than the mid-Albian Stage of the Early Cretaceous (Fig. 2b; Online Resources 1, 2). The minimum age of Abydosaurus is bounded by the Cenomanian-age Dakota Formation, which overlies the Cedar Mountain Formation and represents the transition to a marine facies during the first incursion of the western interior seaway (Eberth et al. 2006).

\section{Diagnosis}

A. mcintoshi is a titanosauriform sauropod based on the presence of camellate pneumaticity in its cervical vertebrae. It is diagnosed by a nasal lateral process directed anteriorly and lacking a posterior hook; maxilla narial process with dorsal articulation for the nasal; nasals overlap asymmetrically on the midline; external nares smaller than the orbit; upper crown apices shifted distally; upper tooth shafts twist through an arc of nearly $45^{\circ}$; and tooth wear present only mesially.

Abydosaurus can be differentiated from other Early Cretaceous North American sauropods on the basis of its postcranial anatomy. The holotypic cervical centra of Abydosaurus are less elongate than those of Paluxysaurus (Rose 2007), the Cloverly sauropod, and probably Sauroposeidon (Wedel et al. 2000), with whose cervical series they do not quite overlap (see Table 1). The humerus referred to Abydosaurus is approximately the same size as that of Cedarosaurus (1.6 m; Tidwell et al. 1999), but is much broader at midshaft ( $26 \mathrm{vs} .18 \mathrm{~cm})$. The humerus of Sonorasaurus is not complete (Ratkevich 1998), but it and other forelimb elements appear to be as gracile as of those Cedarosaurus (M. D'Emic, personal communication). Anterior caudal centra referred to Abydosaurus lack the deep lateral fossae and gentle anterior convexity present in Venenosaurus, and limb elements are more robust (Tidwell et al. 2001). Among cranial remains, the syntypic tooth of Astrodon johnstoni (Leidy 1865) superficially resembles lower teeth of Abydosaurus, but these similarities are not diagnostic among titanosauriforms. Teeth that have been assigned to Pleurocoelus nanus (Lull et al. 1911:pl. 14, Fig. 8) more closely resemble upper teeth of Abydosaurus in the position of the crown apex and localized wear (see above). Despite these similarities, however, we refrain from drawing any taxonomic conclusions at this point due to uncertainty about the type series and constituency of Pleurocoelus nanus, its possible synonymy with Astrodon johnstoni (e.g., Carpenter and Tidwell 2005), and the extremely limited overlap with materials of Abydosaurus.

\section{Description}

A. mcintoshi is unusual among sauropods in being represented by multiple skulls associated with postcranial bones collected from a single quarry (locality DNM 16). In addition to the complete skull found in articulation with four cervical vertebrae (Figs. 3 and 4), Abydosaurus is known from three other individuals, represented by (1) a nearly complete, disarticulated skull, (2) an articulated snout, and (3) a braincase with skull roof (see Online Resource 3). Together, these remains provide the first detailed look at a Cretaceous sauropod skull from the Americas.

The four known skulls of Abydosaurus are nearly the same size, measuring approximately $0.5 \mathrm{~m}$ long and half as tall posteriorly. As in all sauropods, the external nares are retracted posteriorly, and the antorbital and lateral temporal fenestrae approach one another beneath the teardrop-shaped orbit. The premaxillae and maxillae form a broad, elongate, dentigerous muzzle that is offset sharply from the remainder of the skull. As in B. brancai, the dentigerous portion of the skull is slightly deflected relative to the posterior portion of the skull, which is slightly rotated posteroventrally (Fig. 4b). This feature is much more pronounced in narrow-crowned sauropods, such as titanosaurs (e.g., Nemegtosaurus) and diplodocoids (e.g., Diplodocus). The premaxilla and maxilla contact one another along a long suture that extends to the anteroventral edge of the external naris. Ventrally, near the tooth row, the bodies of the premaxilla and maxilla contact in a sinuous, mutually overlapping fashion. Closer to the external nares, the premaxilla and maxilla form a broad, smooth narial fossa. 
Table 1 Cervical centrum elongation in neosauropod dinosaurs

\begin{tabular}{|c|c|c|c|c|c|c|}
\hline Genus (reference) & Cervical \# & Length & Width & Height & Average & $\mathrm{aEI}$ \\
\hline \multirow[t]{3}{*}{ Camarasaurus (McIntosh et al. 1996) } & 3 & 19.1 & 10.7 & 26.0 & 18.3 & 1.0 \\
\hline & 4 & 24.5 & 13.0 & 25.0 & 19.0 & 1.3 \\
\hline & 5 & 31.0 & 16.0 & 26.5 & 20.7 & 1.5 \\
\hline \multirow[t]{2}{*}{ Abydosaurus (this paper) } & 3 & 23.0 & 10.4 & 5.8 & 8.1 & 2.8 \\
\hline & 4 & 32.0 & 10.7 & 7.3 & 9.0 & 3.5 \\
\hline \multirow[t]{3}{*}{ Brachiosaurus brancai (Janensch 1950) } & 3 & 35.2 & 12.3 & 11.6 & 12.0 & 2.9 \\
\hline & 4 & 51.0 & 13.2 & 13.8 & 13.5 & 3.8 \\
\hline & 5 & 65.9 & 17.8 & 15.2 & 16.5 & 4.0 \\
\hline \multirow[t]{3}{*}{ Malawisaurus (Gomani 2005) } & $3 *$ & 20.7 & 4.1 & 4.5 & 4.3 & 4.8 \\
\hline & $4^{*}$ & 25.0 & 6.1 & 4.6 & 5.3 & 4.7 \\
\hline & $5^{*}$ & 32.0 & 6.5 & 6.0 & 6.2 & 5.2 \\
\hline \multirow[t]{3}{*}{ Euhelopus (Wiman 1929) } & 3 & $14.6 \mathrm{e}$ & 3.6 & 4.8 & 4.2 & 3.5 \\
\hline & 4 & $25.0 \mathrm{e}$ & 4.0 & 4.1 & 4.0 & 6.2 \\
\hline & 5 & $26.35 \mathrm{e}$ & 4.6 & 6.5 & 5.5 & 4.8 \\
\hline Cloverly taxon; juvenile individual (M. D’Emic pers. comm.) & $7 *$ & 48.5 & 12.0 & 6.6 & 9.3 & 5.2 \\
\hline Sauroposeidon (Wedel et al. 2000) & $5^{*}$ & 96.0 & 14.5 & 18.0 & 16.3 & 5.9 \\
\hline \multirow[t]{2}{*}{ Paluxysaurus (M. D’Emic pers. comm.) } & $3 *$ & 44.0 & 7.0 & 7.1 & 7.0 & 6.3 \\
\hline & $4 *$ & $67 \mathrm{e}$ & 8.1 & $8 \mathrm{e}$ & 8.0 & 8.3 \\
\hline
\end{tabular}

The elongation of cervical centra has been expressed as centrum length scaled to posterior centrum height (Wilson and Sereno 1998) or to posterior centrum width (Upchurch 1998). Here we scale centrum length to the average of centrum height and width (aEI) to avoid confusing changes in centrum elongation with those in cross-sectional shape as well as to account for deformation. Taxa are listed in order of increasing aEI. All measurements are in centimeters

Asterisks $(*)$ indicate vertebrae whose positions are not known with certainty, $e$ indicates an estimated measurement

The narial fossa is not as well marked or deeply recessed as it is in B. brancai. As in other neosauropods, a prominent preantorbital fenestra opens on the external surface of the maxilla just above the last tooth position. Unlike other macronarians, such as Camarasaurus and B. brancai, the external nares are smaller than the orbits in Abydosaurus. They are exposed in dorsal and lateral views and divided by a narrow, arched internarial bar composed of the nasals posteriorly and the premaxillae anteriorly. The nasal bones meet each other on the midline in an asymmetrically overlapping fashion in which the right nasal sits atop a facet on the left nasal, which itself fits into a facet on the underside of the right. The orbit is the largest skull opening and is bounded dorsally by the postorbital, frontal, and lacrimal bones, which bear subtle ornamentation consisting of an irregular pattern of small bumps and ridges. Ventrally, it is bordered by the jugal, which bears an elongate posterior process that differentiates it from B. brancai and Camarasaurus. The orbit is separated anteriorly from the comparably small antorbital fenestra by the pillar-like lacrimal, which bears a deep anterior process with an anteriorly projecting tip. Posteriorly the orbit is separated by the postorbital and jugal from the lateral temporal fenestra, whose broad base extends beneath it. Dorsally, the frontals are broader transversely than they are long anteroposteriorly, narrowing in breadth towards the front of the skull. As in B. brancai, the lower jaw is slender anteriorly but deepens near the coronoid process, which serves as the attachment point for adductor musculature that closes the jaw. The dentary bifurcates posteriorly into posterodorsal and posteroventral processes, the latter of which bears a small accessory process matching that present in B. brancai (see Online Resource 3-Fig. 2b).

Upper and lower jaws each contain 14 teeth per side that differ in size and shape. Upper teeth have a D-shaped crosssection, with a flat-to-gently convex lingual face and a strongly convex labial face. They are as deep labiolingually as they are mesiodistally and twist $45^{\circ}$ about their long axis towards their apical end (Fig. 4d). In contrast, the lower teeth are typically smaller than corresponding upper teeth, more elliptical in cross-section and do not twist along their length (Fig. 4e). As in narrow-crowned sauropods and $B$. brancai (Calvo 1994; Upchurch and Barrett 2000), the tooth crowns in Abydosaurus do not overlap along the tooth row, and opposing upper and lower teeth met in a one-toone fashion, as evidenced by small, elliptical tooth-to-tooth wear facets restricted to the mesial edge of the crown tips. This wear pattern differs from more basal eusauropods, 
such as Camarasaurus, in which overlapping, interlocking dentitions met in a one-to-two fashion that produced Vshaped wear facets (Madsen et al. 1995).

The first four cervical vertebrae were preserved in articulation with the holotypic skull. Although eroded off above the neurocentral junction, they furnish important information about the neck anatomy of Abydosaurus. The degree of fusion between the centrum and neural arch cannot be determined due to preservation, but it seems clear that they were at least partially fused because part of the neural arch is attached to the centrum. This indicates that the individual is not a young juvenile. However, because other vertebral regions fuse later than the anterior cervical vertebrae in sauropod ontogeny (Ikejiri et al. 2005), even with excellent preservation, we could not determine whether the holotype was a fully mature individual. The atlas apparently was not pneumatized, as in other titanosauriforms (Wilson and Mohabey 2006), but the internal pneumatic architecture of the postatlantal cervical vertebrae is composed of a series of interconnected, thin-walled chambers or camellae that range from the millimeter to centimeter scale (Fig. 4c). This camellate pneumatization (Britt 1993) can be expected to have extended at least to the sacrum, as in other titanosauriforms. External pneumatic fossae (i.e., pleurocoels) are present on the lateral face of the postatlantal cervical centra. They are divided by an oblique vertical strut and occupy most of the lateral face of the centrum. Centrum length increases markedly across the first four cervical vertebrae of Abydosaurus, with the fourth cervical centrum measuring approximately $180 \%$ the length of the axis. As shown in Table 1, Abydosaurus cervical centrum 4 is moderately elongate, 3.5 times longer than the average of its posterior height and width (aEI). This centrum shape is comparable to the value for $B$. brancai $(\mathrm{aEI}=3.8)$ but much lower than values for anterior cervical vertebrae of the long-necked Early Cretaceous brachiosaurids Paluxysaurus $(\mathrm{aEI}=6.3-8.3)$ and Sauroposeidon $(\mathrm{aEI}=$ 5.9). Centrum width in Abydosaurus is 1.5-1.75 times centrum height, and the postaxial centra are opisthocoelous. The cervical ribs hang below the centrum and bear short anterior processes and long posterior processes. The axial rib extends to the fourth cervical vertebra, and other cervical ribs likely extended past at least two vertebrae, forming the ventral bracing system present in the necks of most sauropods and certain other saurischian dinosaurs (Martin et al. 1998).

Other postcranial elements include an articulated sacrum, partial pelvis, and anterior caudal vertebrae, plus a scapula, a partial humerus, and a metacarpus. These elements were associated with the partial articulated skull, DINO 17848 , and the disarticulated skull, DINO 17849 but it cannot be determined which of these skulls pertain to the postcranial assemblage. We judge that the postcranial elements almost certainly pertain to $A$. mcintoshi. Caudal vertebrae resemble those of Brachiosaurus in their swept-back transverse processes that bear a bulge on their ventral surface. The scapula and forelimb elements are more robust than the autapomorphically gracile limb bones of Brachiosaurus. Like Camarasaurus and Brachiosaurus, the scapula of Abydosaurus has a dorsally expanded blade, and the humerus has a well-developed deltopectoral crest and expanded distal end. The metacarpals are arranged in a digitigrade, U-shaped arch, as in other neosauropods. The postcranial materials are still in preparation and will be described in a later contribution.

\section{Discussion}

Phylogenetic relationships of $A$. mcintoshi

In order to resolve the phylogenetic position of Abydosaurus among sauropods, we conducted a cladistic analysis based on the data matrix of Wilson (2002) with modified taxonomic and character scope and with suggested scoring changes (Wilson and Upchurch 2009; see Online Resource 4). Ingroup terminal taxa were restricted to neosauropods, and several genera were bundled into higher-level terminal taxa. The reduced taxonomic scope of the analysis necessitated removal of characters whose scorings do not vary within Neosauropoda, either because they distinguish among basal clades or because they vary between genera subsumed within higher-level terminal taxa. We augmented the data matrix by including autapomorphies of neosauropod genera listed by Wilson (2002: appendix C) that are shared with Abydosaurus. The resultant matrix included 151 characters scored in ten ingroup taxa and two outgroup taxa (Omeisaurus, Shunosaurus) that were chosen based on their completeness and unanimous acceptance of their phylogenetic position outside Neosauropoda.

The low number of terminal taxa allowed for use of "branch-and-bound" treebuilding methods, which guarantee discovery of the shortest tree but not all trees (Swofford 2001). Five most parsimonious trees were discovered (235 steps) that differed in the positions of Jobaria and Haplocanthosaurus within Neosauropoda. Apart from this uncertainty, tree topology is consistent with that of Wilson (2002). Neosauropoda is monophyletic and consists of Diplodocoidea and Macronaria. Diplodocoidea includes the sister taxa Flagellicaudata and Rebbachisauridae, whereas Macronaria includes Camarasaurus, Brachiosaurus (i.e., B. altithorax + B. brancai), and Euhelopus as successive outgroups to Titanosauria (Malawisaurus + Lithostrotia). Abydosaurus could be scored for almost 50\% of the characters, which resolved it within Macronaria as the sister taxon to Brachiosaurus (decay index=3). Abydosau- 
rus is positioned within Titanosauriformes based on the presence of spongy (camellate) presacral vertebrae and resolved as sister taxon to Brachiosaurus by the presence of an anterior process on the lacrimal, narrow separation of the supratemporal fossae on the skull roof, dentary with a divided posteroventral process, and transverse processes of anterior caudal vertebrae with a prominent ventral bulge.

Evolution of tooth shape in sauropods

Sauropod tooth shape has long been characterized as either 'broad crowned' or 'narrow crowned' (Janensch 1929), and the ever-improving sauropod fossil record indicates that whereas both morphs coexisted in Late Jurassic ecosystems, only narrow-crowned forms survived into the latest Cretaceous (Barrett and Upchurch 2005; Wilson 2005). The transition between these two endpoints occurred during the Early Cretaceous, which is an undersampled interval in sauropod history - particularly in North America (Wedel et al. 2000), where they are thought to have gone extinct after the Albian and re-entered from South America or Asia during the Maastrichtian (Lucas and Hunt 1989). A. mcintoshi was part of this general trend of reduction of tooth crown breadth during the Cretaceous.

To examine broad-scale changes in tooth morphology in sauropodomorph dinosaurs, we measured a simple index of tooth crown shape called the Slenderness Index (SI), which is the ratio of crown length to crown breadth (Upchurch 1998). This metric has been used previously to bin sauropods into broad-crowned $(\mathrm{SI} \leq 4.0)$ and narrowcrowned $(\mathrm{SI} \geq 4.0)$ morphs and to identify a gradual replacement of the former by the latter during the Cretaceous (Barrett and Upchurch 2005:128). In Fig. 5, we plot the distribution of SI in all known sauropod teeth and a representative sample of basal sauropodomorph teeth to examine changes in sauropod tooth morphospace during the Mesozoic (see Online Resource 5, 6).

The basal sauropodomorph outgroups to sauropods, generally referred to as 'prosauropods', were the earliest saurischian herbivores (Martínez and Alcober 2009). During their 40 million year history, they occupied a fairly narrow band of tooth crown breadth $(\mathrm{SI}=1.56-2.43)$ that can be regarded as the primitive condition for sauropods. For nearly 20 million years, prosauropods coexisted with basal sauropods, with which they overlapped in tooth shape space. Notably, however, basal sauropods attained broader tooth crown proportions than did prosauropods early in their history and achieved their broadest crown proportions by the end of the Middle Jurassic (SI=1.16). Although prosauropods and basal sauropods overlap in tooth shape space, it is not known whether they competed for similar resources; very few horizons (e.g., lower and upper Elliot Formation) preserve both basal sauropodomorphs and basal

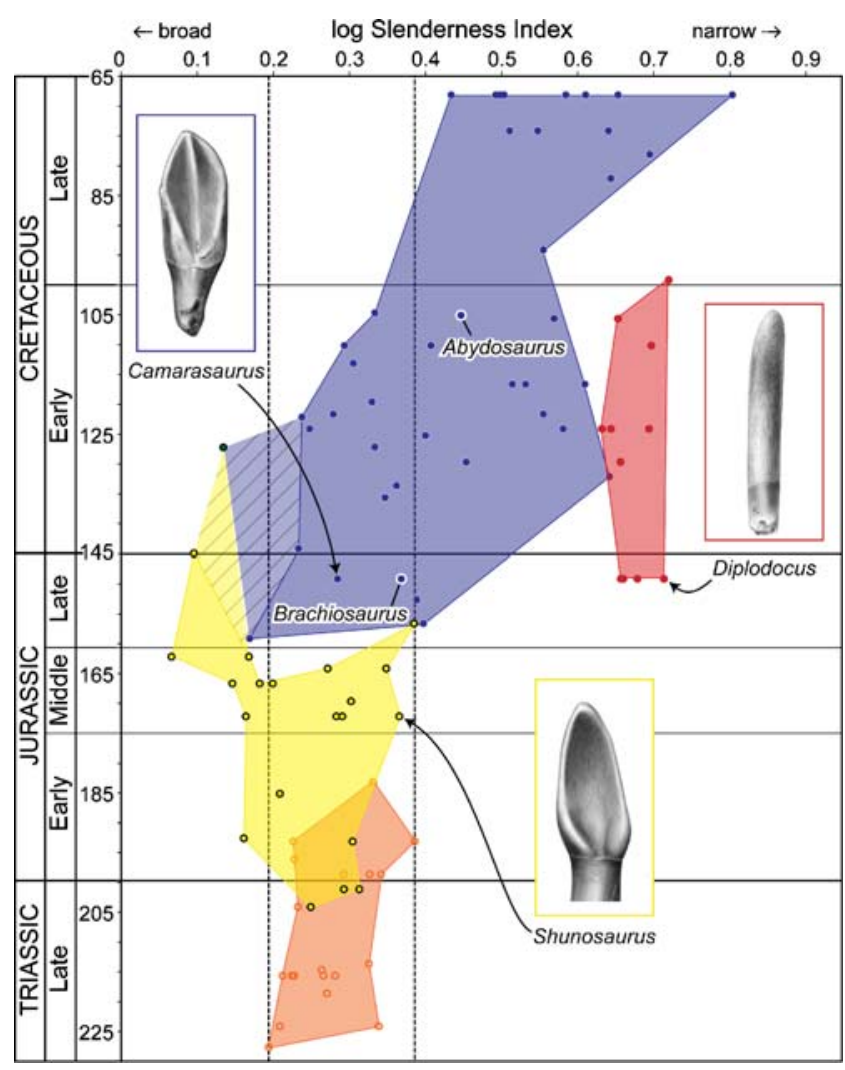

Fig. 5 Temporal patterns in sauropodomorph tooth shape. The plot shows tooth slenderness index (crown height/crown width) for sauropodomorph genera throughout the Mesozoic (see Online Resource 5 to match sauropod species and SI). SI has been logged to show proportional differences between taxa. The orange field indicates non-sauropod sauropodomorphs ('prosauropods'), the yellow field indicates basal sauropods, the red field indicates diplodocoids, and the blue field indicates macronarians. Half-tone drawings show representative members of each group (not to scale). The dashed gray vertical lines indicate the range of tooth breadths present in 'prosauropods', which may be used as a proxy for the primitive condition in sauropods. Phylogenetic uncertainty regarding the affinities of Jobaria is indicated by cross-hatching; the transparent blue and yellow fields indicate the shape of the tooth space when Jobaria is included within macronarians and basal sauropods, respectively. Time scale based on Gradstein et al. (2004)

sauropods (Yates and Kitching 2003; Knoll 2004, 2005; Yates et al. 2004).

There is very little temporal overlap between basal sauropods and neosauropods (macronarians and diplodocoids). In fact, the original partition of sauropods into 'eosauropods' (i.e., basal sauropods) and neosauropods took advantage of their stratigraphic distribution on either side of the Middle-Late Jurassic boundary (Bonaparte 1986). Although this pattern still holds generally, at least one Cretaceous genus potentially falls outside the neosauropod radiation (Jobaria; Sereno et al. 1999). More recent analyses have suggested Jobaria is a basal macronarian (e.g., Upchurch et al. 2004; Remes et al. 2009) of potentially older stratigraphic age (Rauhut and López- 
Arbarello 2009). If either of these hypotheses is correct, then basal sauropods are restricted to infra-Cretaceous sediments (cross-hatching in Fig. 5). The first reduction in relative crown breadth beyond the primitive 'prosauropod' range appeared in the Late Jurassic, with the appearance of diplodocoids such as Diplodocus and Apatosaurus. Diplodocoids are separated from contemporaneous neosauropods by a notable SI gap, which may have been bridged by the currently unsampled phylogenetic intermediates present during the early Late Jurassic or Middle Jurassic. The widest range of crown proportions was achieved during the Late Jurassic, after which neosauropods (diplodocoids plus macronarians) underwent a dramatic shift towards narrower crown proportions.

The neosauropod subgroups Macronaria and Diplodocoidea coexisted for nearly 50 million years but did not overlap in tooth shape space. During the Late Jurassic and Early Cretaceous, macronarians occupied a wide range of tooth crown shapes but never attained the narrow proportions of diplodocoids. After the extinction of diplodocoids at the beginning of the Late Cretaceous, macronarians radiated into the narrow tooth crown shape space previously occupied by diplodocoids. This, combined with the extinction of broad-crowned sauropods ca. 125 million years ago, led to a sauropod fauna consisting exclusively of narrow-crowned taxa, as previously mentioned (Barrett and Upchurch 2005; Wilson 2005). By the latest Cretaceous, all sauropod teeth are narrower than the narrowest 'prosauropod' or basal sauropod teeth, and titanosaurs are the only remaining sauropod lineage (Fig. 5).

A. mcintoshi has an intermediate crown breadth that is narrower than that of 'prosauropods' and basal sauropods but not nearly as narrow as that of diplodocoids or titanosaurs. Abydosaurus lies within a cluster of Early Cretaceous tooth forms that have narrower crown breadths than their antecedents, marking a shift in crown breadth that appears to be independent of changes to narrow crown breadths in titanosaurs in the Cretaceous and in diplodocoids in the Late Jurassic. This shift did not result in major changes in sauropod absolute and relative diversity and absolute abundance, which remain relatively stable throughout the Cretaceous (Butler et al. 2009: fig. 1) apart from a minor decline in the mid-Cretaceous that coincides with a drop in the number of dinosaur-bearing formations (Upchurch and Barrett 2005: fig. 3.6; Barrett et al. 2009).

Sauropod-plant coevolution?

Although numerous authors have suggested a connection between the origin and radiation of angiosperms and changes in herbivorous dinosaur faunas (e.g., Bakker 1978), recent analyses have unanimously concluded that there is no demonstrable coevolutionary relationship be- tween major events in dinosaur and plant evolution (Sereno 1997; Weishampel and Jianu 2000; Barrett and Willis 2001; Barrett and Rayfield 2006; Butler et al. 2009). To examine potential links between the shift in Cretaceous sauropod dentitions detailed above (Fig. 5) with changes in contemporaneous floras, below we explore the functional implications of narrow-crowned dentitions.

Reduction in tooth crown breadth is correlated with increased packing of teeth into the jaws. In diplodocoids, for example, narrow crowns are associated with as many as seven replacement teeth per tooth position and tooth replacement rates of every 30 days (Nigersaurus; Sereno et al. 2007) or every 35 days (Diplodocus; D'Emic et al. 2009). These rates are higher than those of the broadcrowned sauropod Camarasaurus, which replaces its teeth every 62 days (J. Whitlock, unpublished data). Narrowcrowned sauropods replace their teeth faster than contemporaneous ornithischian dinosaurs with dental batteries, the fastest of which replaces every 50 days (Edmontosaurus; Erickson 1996). In addition to differences in tooth replacement rates, tooth formation times are nearly twice as fast for the narrow-crowned sauropod Diplodocus compared to the broad-crowned Camarasaurus (ca. 185 days vs. ca. 315 days; J. Whitlock, unpublished data). Narrow-crowned macronarians such as titanosaurs have not been histologically sampled to measure replacement rates, but these can be estimated by comparing relative sizes of functional and replacement teeth. In rapidly replacing dentitions, a functional tooth and its replacement teeth are close to one another in size, whereas in slowly replacing dentitions they are more disparate in size. Like diplodocoids, narrow-crowned macronarians have tooth families composed of teeth that are close to one another in size, implying they too replaced rapidly (D'Emic et al. 2009). We hypothesize that the high replacement rates associated with narrow-crowned sauropod dentitions suggest that they were subjected to high rates of wear, which may have been caused by one or more of several factors, including: (1) mechanics of biting or chewing; (2) diet; or (3) feeding ecology.

Mechanics of biting or chewing Despite similarities in the shapes of crania of narrow-crowned sauropod taxa, some of which have elongate skulls with an anteriorly restricted dentition (see below), there is no evidence that the mechanics of these skulls would increase wear on teeth. In fact, the magnitude of loads generated by adductor musculature placed on terminally positioned dentition in an elongate skull is expected to be lower than those generated by a shorter-jawed form with a proportionately longer dentigerous region. In addition, differences in the direction of bite force (e.g., shift from orthal to propalinal stroke) would not be expected to dramatically increase wear rates 
in the absence of other differences. This suggests that the observed changes in crown breadth may be related to something other than jaw mechanics, such as a shift in diet and/or feeding ecology.

Diet The transition from a broad range of crown breadths to predominantly, and later exclusively, narrow dentitions took place in the Cretaceous (Fig. 5), during which time a major shift in global floral composition occurred. In the Early Cretaceous, several major plant groups contributed subequally to global abundances, but from the Albian until the end-Cretaceous angiosperms and conifers comprised nearly $80 \%$ of vascular plant occurrences (Butler et al. 2009: Fig. 2). This change to a conifer-angiosperm predominated flora suggests that sauropods would, on average, encounter these plants more often than others. Despite this general correlation between changes in sauropod tooth shape and conifer-angiosperm abundances, these plants are not especially abrasive and would not have produced comparatively high rates of wear. Living conifers and angiosperms have been shown to have lower silica content overall than other plant groups, even if certain subgroups such as grasses were silica accumulators (Hodson et al. 2005). Although there are records of modern grasses in the Cretaceous, they were not ecologically predominant (Prasad et al. 2005). Apart from grasses, there are several nonangiosperm, non-conifer plants with Mesozoic representatives (e.g., the pteridophyte Equisetum, the fern Osmundia) that have been demonstrated to be both nutritious and digestible (Hummel et al. 2008) and highly abrasive (Hodson et al. 2005).

These silica accumulating plants are all potential wearinducing foodstuffs for sauropod dinosaurs, but there is no direct evidence that sauropods ate them. In fact, no bona fide coprolites or enterolites have been directly associated with sauropod skeletons, and no plant remains have been found in situ on sauropod dentitions. The sauropod stomach contents reported by Stokes (1964) were not found in place within an articulated skeleton and were later determined to be part of a laterally extensive, twig laden, lacustrine deposit (J. H. Madsen and W. D. Tidwell, personal communication, 2002). They provide a less convincing case of direct association than do other recent discoveries from non-sauropod dinosaurs (e.g., Molnar and Clifford 2000; Varricchio 2001; Tweet et al. 2008). A case for indirect association of coprolites with sauropods was made by Matley (1939), who described abundant, wellpreserved coprolites from the Late Cretaceous Lameta Formation of India. There, sauropods are abundant and the only large-bodied herbivores known from the landmass. The Indian coprolites contain grass phytoliths as well soft tissues of other angiosperms, gymnosperms, and pteridophytes, indicating a diet of mixed composition and abrasiveness (Mohabey and Samant 2003; Prasad et al. 2005).

Feeding ecology Although narrow-crowned sauropods do not form a monophyletic group, there are cranial features shared between certain members of the two main lineages. Reduction of tooth breadth in both derived diplodocoids (e.g., Diplodocus, Nigersaurus) and derived titanosaurs (e.g., Rapetosaurus, Nemegtosaurus) resulted in dentitions that were positioned anteriorly in the jaws (Curry Rogers and Forster 2001). Anteriorly restricted dentition, along with an elongate skull shape, squared jaws, elevated tooth replacement rates, microwear data, and vertical head orientation were interpreted as adaptations to a lowbrowsing feeding strategy in Nigersaurus (Sereno et al. 2007), a feeding strategy suggested to be general for diplodocoids (Upchurch and Barrett 2000). Comparable data is not yet available for head orientation in titanosaurs, but the presence of an elongate skull with anteriorly restricted, rapidly replacing narrow crowns may suggest that at least some of them were also low browsers.

In sum, the shift to rapidly replacing, high-wear dentitions in Cretaceous sauropods does not appear to be related to any major change in global floral diversity, despite its coincidence with increased abundance of conifers and angiosperms. Instead, this pattern may be explained by a shift in diet to highly abrasive vegetation or to a shift in feeding ecology to low browsing, possibilities to be explored by future work.

\section{Sauropod skulls: spartan design}

Sauropods are notable among dinosaurian herbivores for their relatively simple and static skull design. Even the bizarre Nigersaurus represents an extreme version of a diplodocoid rather than a substantially neomorphic form (Sereno et al. 2007). The absence in sauropods of complex masticatory adaptations (e.g., beaks, cheeks, kinesis, and heterodonty) and cranial display structures (e.g., crests, frills, and ornamentation) - all of which are present within ornithischian herbivores - is somewhat surprising given the success of sauropod dinosaurs. However, the proportions of sauropod skeletons may offer insight into this counterintuitive pattern.

The sauropod body plan was acquired quite early in their evolutionary history and remained relatively unchanged during the Mesozoic. All sauropods have a small head, long neck, long tail, and deep bodies supported by four columnar legs. Even the relatively large head of $B$. brancai only accounts for approximately $1 / 200$ th of total body volume (0.4\%; Gunga et al. 2008). This proportion was probably similar for Abydosaurus but even smaller for sauropods 
such as Diplodocus. In contrast, the heads of ornithischian herbivores are an order of magnitude larger relative to body volume. The head of Edmontosaurus accounts for approximately 1/30th body volume (3.2\%; Bates et al. 2009). Although the body mass of B. brancai $(38,000 \mathrm{~kg}$; Gunga et al. 2008) is nearly 50 times that of Edmontosaurus (813.25 kg; Bates et al. 2009), the observed difference in body proportions does not appear to be mass-dependent. The prosauropod Plateosaurus, which has a body mass (630-912 kg) comparable to Edmontosaurus, has a head volume that is approximately $1 / 125$ body volume $(0.8$ $0.9 \%$; Gunga et al. 2007).

We conclude that whereas complex intraoral processing and cranial display structures may have been effective for relatively large-headed, short-necked ornithischians, they may not have been advantageous for sauropods. Instead, sauropods evolved small skulls and elongate necks early in their evolutionary history. They adopted a strategy of maximizing intake by specialized cropping with little to no processing and maximizing feeding envelope by changes in the length, mobility, support, and neutral pose of the neck.

Acknowledgments S. Madsen and the late A. Elder (both formerly of Dinosaur National Monument) and their crews excavated and prepared some of the specimens, including the holotypic skull; Brigham Young University also collected and prepared material from the site. Fire Operations at DINO provided helicopter transport of some of the field jackets. Locality photo by K. Hamblin. We thank B. Miljour for assistance with the figures. G. Gehrels and V. Valencia (Arizona Laserchron Center) are gratefully acknowledged for assistance with U$\mathrm{Pb}$ dating. P. Barrett, M. D'Emic, C. Strömberg, and P Upchurch provided useful comments on an earlier draft of this paper. M. D'Emic provided measurements for the Cloverly taxon and Paluxysaurus, and M. Wedel provided additional measurements of Sauroposeidon. Collections research for JAW was supported by NSF DEB-0640434 and a Woodrow Wilson National Fellowship Foundation Career Enhancement Fellowship for Junior Faculty.

Open Access This article is distributed under the terms of the Creative Commons Attribution Noncommercial License which permits any noncommercial use, distribution, and reproduction in any medium, provided the original author(s) and source are credited.

\section{References}

Bakker RT (1978) Dinosaur feeding behaviour and the origin of flowering plants. Nature 274:661-663. doi:10.1038/274661a0

Barrett PM, Willis KJ (2001) Did dinosaurs invent flowers? Dinosaurangiosperm coevolution revisited. Biol Rev 76:411-447. doi: $10.1017 /$ S1464793101005735

Barrett PM, Upchurch P (2005) Sauropodomorph diversity through time: macroevolutionary and paleoecological implications. In: Curry Rogers K, Wilson JA (eds) The sauropods: evolution and paleobiology. University of California Press, Berkeley, pp 125-156

Barrett PM, Rayfield EJ (2006) Ecological and evolutionary implications of dinosaur feeding behaviour. Trends Ecol Evol 21:217224. doi:10.1016/j.tree.2006.01.002
Barrett PM, McGowan AJ, Page V (2009) Dinosaur diversity and the rock record. Proc Roy Soc London B 276:2667-2674. doi:10.1098/rspb.2009.0352

Bates KT, Manning PL, Hodgetts D, Sellers WI (2009) Estimating mass properties of dinosaurs using laser imaging and $3 \mathrm{D}$ computer modelling. PLoS ONE 4:e4532. doi:10.1371/journal. pone. 0004532

Blakey RC (2006) Global paleogeographic views of earth history-late Precambrian to recent. http://jan.ucc.nau.edu/ rcb7/globaltext $2 . h t m l$. Accessed 19 May 2006

Bonaparte JF (1986) Les dinosaures (Carnosaures, Allosauridés, Sauropodes, Cétiosauridés) du Jurassique moyen de Cerro Cóndor (Chubut, Argentina). Ann Paléontol 72:325-386

Britt BB (1993) Pneumatic postcranial bones in dinosaurs and other archosaurs. Dissertation, University of Calgary

Britt BB, Scheetz RD, Dangerfield A (2008) A suite of dermestid beetle traces on dinosaur bone from the Upper Jurassic Morrison Formation, Wyoming, USA. Ichnos 15:59-71. doi:10.1080/ 10420940701193284

Butler RJ, Barrett PM, Kenrick P, Penn MG (2009) Diversity patterns amongst herbivorous dinosaurs and plants during the Cretaceous: implications for hypotheses of dinosaur/angio sperm co-evolution. J Evol Biol 22:446-459. doi:10.1111/ j.1420-9101.2008.01680.x

Calvo JO (1994) Jaw mechanics in sauropod dinosaurs. Gaia 10:183-193

Carpenter K, Tidwell V (2005) Reassessment of the early Cretaceous sauropod Astrodon johnsoni [sic] Leidy 1865 (Titanosauriformes). In: Tidwell V, Carpenter K (eds) Thunder-lizards: the Sauropodomorph Dinosaurs. Indiana University Press, Bloomington, pp 78-114

Curry Rogers K, Forster CA (2001) The last of the dinosaur titans: a new sauropod from Madagascar. Nature 412:530-534. doi:10.1038/ 35087566

D’Emic MD, Whitlock JA, Smith KM, Wilson JA, Fisher DC (2009) The evolution of tooth replacement rates in sauropod dinosaurs. J Vert Paleontol 29:84A

Eberth DA, Britt BB, Scheetz R, Stadtman KL, Brinkman DB (2006) Dalton Wells: geology and significance of debris-flow-hosted dinosaur bonebeds in the Cedar Mountain Formation (Lower Cretaceous) of eastern Utah, USA. Palaeogeog Palaeoclimatol Palaeoecol 236:217-245. doi:10.1016/j.palaeo.2005.11.020

Erickson GM (1996) Incremental lines of von Ebner in dinosaurs and the assessment of tooth replacement rates using growth line counts. PNAS 93:14623-14627

Gomani EM (2005) Sauropod dinosaurs from the Early Cretaceous of Malawi, Africa. Palaeontol Electron 8:1-37

Gradstein FM, Ogg JG, Smith AG (2004) A geologic time scale 2004. Cambridge University Press, Cambridge

Gunga HC, Suthau T, Bellman A, Friedrich A, Schwanebeck T et al (2007) Body mass estimations for Plateosaurus engelhardti using laser scanning and 3D reconstruction methods. Naturwiss 94:623-630. doi:10.1007/s00114-007-0234-2

Gunga HC, Suthau T, Bellman A, Stoinski S, Friedrich A et al (2008) A new body mass estimation of Brachiosaurus brancai Janensch, 1914 mounted and exhibited at the Museum of Natural History (Berlin, Germany). Fossil Record 11:33-38. doi:10.1002/ mmng.200700011

Hodson MJ, White PJ, Mead A, Broadley MR (2005) Phylogenetic variation in the silicon composition of plants. Ann Bot 96:10271046. doi:10.1093/aob/mci255

Hummel J, Gee CT, Südekum KH, Sander PM, Nogge G, Clauss M (2008) In vitro digestibility of fern and gymnosperm foliage: implications for sauropod feeding ecology and diet selection. Proc Roy Soc B 275:1015-1021. doi:10.1098/rspb.2007.1728

Ikejiri T, Tidwell V, Trexler DL (2005) New adult specimens of Camarasaurus lentus highlight ontogenetic variation within the 
species. In: Tidwell V, Carpenter K (eds) Thunder-Lizards: the Sauropodomorph Dinosaurs. Indiana University Press, Bloomington, pp 154-186

Janensch W (1929) Material und Formengehalt der Sauropoden in der Ausbeute der Tendaguru Expedition. Palaeontographica 2(Supp 7): $1-34$

Janensch W (1950) Die Wirbelsäule der von Brachiosaurus brancai. Palaeontographica 3(Supp 7):27-92

Knoll F (2004) Review of the tetrapod fauna of the "Lower Stromberg Group" of the main Karoo Basin (southern Africa): implication for the age of the Lower Elliot Formation. Bull Soc Géol France 175:73-83. doi:10.2113/175.1.73

Knoll F (2005) The tetrapod fauna of the Upper Elliot and Clarens formations in the main Karoo Basin (South Africa and Lesotho). Bull Soc Géol France 176:81-91. doi:10.2113/176.1.81

Leidy J (1865) Cretaceous reptiles of the United States. Smithson Contr Knowl 192:1-135

Lucas SG, Hunt AP (1989) Alamosaurus and the sauropod hiatus in the Cretaceous of the North American Western Interior. Geol Soc America Sp Pap 238:75-85

Lull RS, Clark WB, Berry EW (1911) Systematic paleontology of the lower Cretaceous deposits of Maryland: Vertebrata. Maryland Geological Survey Systematic Reports 1911:171-211

Madsen JH Jr, McIntosh JS, Berman DS (1995) Skull and atlasaxis complex of the Upper Jurassic sauropod Camarasaurus Cope (Reptilia: Saurischia). Bull Carnegie Mus Nat Hist 31:1-115

Marsh OC (1878) Principal characters of American Jurassic dinosaurs. Pt I Am J Sc 16:411-416

Martin J, Martin-Rolland V, Frey E (1998) Not cranes or masts, but beams: the biomechanics of sauropod necks. Oryctos 1:113-120

Martínez RN, Alcober OA (2009) A basal sauropodomorph (Dinosauria: Saurischia) from the Ischigualasto Formation (Triassic, Carnian) and the early evolution of Sauropodomorpha. PLoS ONE 4:e4397. doi:10.1371/journal.pone.0004397

Matley CA (1939) The coprolites of Pijdura, Central Provinces. Rec Geol Surv India 74:535-547

McIntosh JS, Miles CA, Cloward KC, Parker JR (1996) A new nearly complete skeleton of Camarasaurus. Bull Gunma Mus Nat Hist $1: 1-87$

Mohabey DM, Samant B (2003) Floral remains from Late Cretaceous faecal mass of sauropods from central India: implication to their diet and habitat. Gondwana Geol Mag sp vol 6:225-238

Molnar RE, Clifford HT (2000) Gut contents of a small ankylosaur. J Vertebr Paleontol 20:194-196

Prasad V, Strömberg CAE, Alimohammadian H, Sahni A (2005) Dinosaur coprolites and the early evolution of grasses and grazers. Science 310:1177-1180. doi:10.1126/science.1118806

Ratkevich R (1998) New Cretaceous brachiosaurid dinosaur, Sonorosaurus thompsoni gen. et sp. nov., from Arizona. J Ariz-Nev Acad Sci 31:71-81

Rauhut OWM, López-Arbarello A (2009) Considerations on the age of the Tiouaren Formation (Iullemmeden Basin, Niger, Africa): implications for Gondwanan Mesozoic terrestrial vertebrate faunas. Palaeogeog Palaeoclim Palaeoecol 271:259-267. doi:10.1016/j.palaeo.2008.10.019

Remes K, Ortega F, Fierro I, Joger U, Kosma R et al (2009) A new basal sauropod dinosaur from the Middle Jurassic of Niger and the early evolution of Sauropoda. PLoS ONE 4:e6924. doi:10.1371/journal.pone.0006924

Riggs ES (1904) Structure and relationships of opisthocoelian dinosaurs. Part II: the Brachiosauridae. Field Columbian Museum Geol Ser 2:229-248

Rose PJ (2007) A new titanosauriform sauropod (Dinosauria: Saurischia) from the Early Cretaceous of central Texas and its phylogenetic relationships. Palaeontol Electronica 10:1-65, http://palaeo-electronica.org/paleo/2007_2/00063/index.html
Salgado L, Coria RA, Calvo JO (1997) Evolution of titanosaurid sauropods. I: Phylogenetic analysis based on the postcranial evidence. Ameghiniana 34:3-32

Sereno PC (1986) Phylogeny of the bird-hipped dinosaurs (Order Ornithischia). Nat Geog Res 2:234-256

Sereno PC (1997) The origin and evolution of dinosaurs. Ann Rev Earth Plan Sci 25:435-489. doi:10.1146/annurev.earth.25.1.435

Sereno PC (2007) Basal Sauropodomorpha: historical and recent phylogenetic hypotheses, with comments on Ammosaurus major (Marsh, 1889). Sp Pap Paleontol 77:261-289

Sereno PC, Beck AL, Dutheil DB, Larsson HCE, Lyon GH et al (1999) Cretaceous sauropods from the Sahara and the uneven rate of skeletal evolution among dinosaurs. Science 286:1342-1347

Sereno PC, Wilson JA, Witmer LM, Whitlock JA, Maga A et al (2007) Structural extremes in a Cretaceous dinosaur. PLoS ONE 2:e1230. doi:10.1371/journal.pone. 0001230

Stokes WL (1964) Stomach contents of a sauropod dinosaur. Science 143:576-577

Swofford DL (2001) PAUP*: phylogenetic analysis using parsimony (*and other methods), Version 4.07b. Sinauer, Sunderland

Taylor MP (2009) A re-evaluation of Brachiosaurus altithorax Riggs 1903 (Dinosauria, Sauropoda) and its generic separation from Giraffatitan brancai. J Vertebr Paleontol 29:787-806. doi:10.1671/039.029.0309

Tidwell V, Carpenter K, Brooks W (1999) New sauropod from the Lower Cretaceous of Utah, USA. Oryctos 2:21-37

Tidwell V, Carpenter K, Meyer S (2001) New titanosauriform (Sauropoda) from the poison strip member of the cedar mountain formation (Lower Cretaceous), Utah. In: Tanke D, Carpenter K (eds) Mesozoic vertebrate life. Indiana University Press, Bloomington, pp 139-165

Tweet JS, Chin K, Braman DR, Murphy NL (2008) Probable gut contents within a specimen of Brachylophosaurus canadensis (Dinosauria: Hadrosauridae) from the Upper Cretaceous Judith River Formation of Montana. Palaios 23:624-635. doi:10.2110/ palo.2007.p07-044r

Upchurch P (1995) Evolutionary history of sauropod dinosaurs. Phil Trans Roy Soc London B 349:365-390

Upchurch P (1998) The phylogenetic relationships of sauropod dinosaurs. Zool J Linn Soc 124:43-103

Upchurch P, Barrett PM (2000) The evolution of sauropod feeding mechanisms. In: Sues HD (ed) Evolution of herbivory in terrestrial vertebrates. Cambridge University Press, Cambridge, pp 79-122

Upchurch P, Barrett PM (2005) Phylogenetic and taxic perspectives on sauropod diversity. In: Curry Rogers K, Wilson JA (eds) The sauropods: evolution and paleobiology. University of California Press, Berkeley, pp 104-124

Upchurch P, Barrett PM, Dodson P (2004) Sauropoda. In: Weishampel DB, Dodson P, Osmólska H (eds) The dinosauria, 2nd edn. University of California Press, Berkeley, pp 259-324

Upchurch P, Barrett PM, Zhao X, Xing X (2007) A re-evaluation of Chinshakiangosaurus chunghoensis Ye vide Dong 1992 (Dinosauria, Sauropodomorpha): implications for cranial evolution in basal sauropod dinosaurs. Geol Mag 144:247-262. doi:10.1017/ S0016756806003062

Varricchio DJ (2001) Gut contents from a Cretaceous tyrannosaurid: implications for theropod dinosaur digestive tracts. J Paleontol 75:401-406. doi:10.1666/0022-3360(2001)075<0401: GCFACT $>2.0 . \mathrm{CO} ; 2$

Wedel MJ, Cifelli RL, Sanders RK (2000) Osteology, paleobiology, and relationships of the sauropod dinosaur Sauroposeidon. Acta Palaentol Polonica 45:343-388

Weishampel DB, Jianu CM (2000) Plant-eaters and ghost lineages: dinosaurian herbivory revisited. In: Sues HD (ed) Evolution of herbivory in terrestrial vertebrates. Cambridge University Press, Cambridge, pp 123-143 
Wilson JA (2002) Sauropod dinosaur phylogeny: critique and cladistic analysis. Zool J Linn Soc 136:217-276. doi:10.1046/j.10963642.2002.00029.x

Wilson JA (2005) Redescription of the Mongolian sauropod Nemegtosaurus mongoliensis Nowinski (Dinosauria: Saurischia) and comments on Late Cretaceous sauropod diversity. J Sys Palaeontol 3:283-318. doi:10.1017/S1477201905001628

Wilson JA, Sereno PC (1998) Early evolution and higher-level phylogeny of sauropod dinosaurs. Soc Vertebr Paleontol Mem $5: 1-68$

Wilson JA, Mohabey DM (2006) A titanosauriform (Dinosauria: Sauropoda) axis from the Lameta Formation (Upper Cretaceous: Maastrichtian) of Nand, central India. J Vertebr Paleontol
26:471-479. doi:10.1671/0272-4634(2006) 26[471:ATDSAF] 2.0.CO;2

Wilson JA, Upchurch P (2009) Redescription and reassessment of the phylogenetic affinities of Euhelopus zdanskyi (Dinosauria: Sauropoda) from the Early Cretaceous of China. J Sys Palaeontol 7:1-41

Wiman C (1929) Die Kreide-Dinosaurier aus Shantung. Palaeontol Sinica (ser C) 6:1-67

Yates A, Kitching JW (2003) The earliest known sauropod dinosaur and the first steps towards sauropod evolution. Proc Roy Soc London B 270:1753-1758. doi:10.1098/rspb.2003.2417

Yates A, Hancox PJ, Rubidge BS (2004) First record of a sauropod dinosaur from the upper Elliot Formation (Early Jurassic) of South Africa. S Afr J Sci 100:504-506 